\title{
The use of preexposure treatments for HIV prophylaxis
}

\author{
This article was published in the following Dove Press journal: \\ HIVIAIDS - Research and Palliative Care \\ 2 February 2012 \\ Number of times this article has been viewed
}

\author{
Adrian Majid \\ Robert R Redfield \\ Bruce L Gilliam \\ Institute of Human Virology, \\ University of Maryland School \\ of Medicine, Baltimore, MD, USA
}

Correspondence: Bruce L Gilliam

725 West Lombard St, Baltimore,

MD 21201 , USA

$\mathrm{Tel}+|4| 0706$ I372

Fax+I 4107061992

Email bgilliam@ihv.umaryland.edu

\begin{abstract}
Infection with human immunodeficiency virus remains a global concern with a significant number of incident infections still reported worldwide. The use of prophylaxis prior to exposure to the virus to prevent infection has been a growing area of recent research. Results in nonhuman primates and clinical trials in high-risk patient populations using preexposure prophylaxis have shown promising results in terms of efficacy and safety, especially relating to oral preexposure prophylaxis. The potential use of oral antiretroviral agents traditionally used for human immunodeficiency virus treatment as prophylaxis raises interesting considerations, such as the best agents available for such a role, long-term safety in healthy individuals, and the potential development of resistance to these agents should infection occur. From a public health perspective, the cost-effectiveness of implementing this preventive strategy has not been fully defined at this point in time.
\end{abstract}

Keywords: preexposure prophylaxis, human immunodeficiency virus, tenofovir, maraviroc

\section{Introduction}

Human immunodeficiency virus (HIV) remains a significant public health challenge. There are currently more than 33 million people living with acquired immune deficiency syndrome (AIDS) worldwide. ${ }^{1}$ Despite increasing access to antiretroviral drugs, the Joint United Nations Program on HIV/AIDS reported a total of 2.7 million new infections worldwide in $2008 .^{1}$

Efforts to curb transmission by treating HIV-infected patients in serodiscordant couples $^{2,3}$ and prophylaxis to prevent mother-to-child transmission ${ }^{4}$ have likely played a significant role in decreasing incident infections. But these measures, along with longstanding public health measures, have not been able to prevent incident infections. In the United States, for example, there are an estimated 56,000 cases of incident HIV infections per year. ${ }^{5,6}$ Men who have sex with men (MSM) account for $53 \%$ of these cases.

In order to decrease these incident infections, new strategies for preventing HIV transmission, especially among high-risk groups, have emerged. Preexposure prophylaxis (PreP), one of these approaches, involves the use of topical or oral agents in HIV-uninfected individuals prior to exposure to the virus in order to prevent HIV acquisition. In addition, PreP may potentially play a role in attenuating the natural history of HIV disease progression in patients who become infected, reducing morbidity and decreasing infectiousness to others. ${ }^{7}$

In this review, the current knowledge regarding the use of topical and oral agents for PreP will be presented. The ideal pharmacokinetics for efficacy of PreP agents, 
and the results of preclinical animal models and human clinical trials of PreP will be discussed. Additionally, the debate regarding the long-term safety of PreP, the implications of developing resistant HIV on PreP, and the overall cost-effectiveness of implementing PreP as a prevention strategy will be explored.

\section{Microbicides}

Microbicides are topical products that can be applied to either the vaginal or rectal mucosa to prevent HIV transmission. The idea for microbicides developed as a means by which women could have control over their risk of HIV infection and potentially prevent other sexually transmitted infections. ${ }^{8,9}$ Research in the field grew as the percentage of women infected with HIV increased, especially in Sub-Saharan Africa, where $67 \%$ of the HIV-infected individuals worldwide live. ${ }^{1}$

Unfortunately, over the past decade, research into various microbicides has not yielded compelling data for their efficacy. Clinical trials of surfactants, agents that disrupt the cell membranes of viruses and bacteria, and polyanions (eg, Carraguard ${ }^{\circledR}$ cellulose sulfate, PRO 2000) showed promise in in vitro and in animal studies, ${ }^{10-13}$ but did not show statistically significant differences between rates of HIV acquisition in clinical trials. ${ }^{14-19}$ In fact, nonoxynol-9 and cellulose sulfate were associated with an increased risk of HIV acquisition in women, likely due to a rapid and sustained reduction in transepithelial resistance..$^{20,21}$

Due to the lack of efficacy of these microbicides, focus has shifted toward agents that might be more specific for HIV. Tenofovir (TDF), a nucleotide analog that blocks the reverse transcription of HIV in the host cell, has been studied as a microbicide in a $1 \%$ gel form, both by itself and in combination with emtricitabine (FTC), another nucleoside analog that comes in a $5 \%$ gel. ${ }^{20}$ These agents have been chosen for their long half-lives (TDF: $>60$ hours, FTC: $\sim 40$ hours), allowing them to persist in tissues long after extracellular concentrations decline.

Studies of macaques exposed to simian immunodeficiency virus (SIV) and simian-human immunodeficiency virus (SHIV) vaginally and rectally have been used as animal models for studying HIV acquisition. One study revealed that a $1 \%$ TDF gel applied rectally to rhesus macaques offered a statistically significant partial efficacy against SIV. ${ }^{22}$ In one study, the vaginal application of $1 \%$ TDF alone or in combination with 5\% FTC two times per week fully protected macaques from a total of 20 exposures to homologous SHIV. ${ }^{23}$ These studies are further outlined in Table 1.
Building on these animal models, the Center for the AIDS Programme of Research in South Africa 004 clinical study, ${ }^{24}$ a double-blind randomized controlled trial of about 900 South African HIV-uninfected higher-risk women ages 18-40, compared rates of HIV acquisition with TDF gel versus placebo gel. The HIV incidence in the TDF gel arm was 5.6 per 100 women years compared with 9.1 per 100 in the placebo arm, which was statistically significant. In those with $>80 \%$ adherence, the HIV incidence was $54 \%$ lower in the TDF gel arm. Although there was documented efficacy, low rates of adverse reactions, and no documentation of resistance to TDF developing in women who acquired HIV, rates of HIV transmission were still high. Therefore, this strategy needs to be used in conjunction with other preventive strategies, such as condoms, in order for it to be fully beneficial.

Other antiretroviral microbicides currently in multiple phase I and II clinical trials are dapivirine and UC 781, two non-nucleoside reverse-transcriptase inhibitors (NNRTIs). ${ }^{25,26}$ From data available, both seem to attain high levels in cervicovaginal fluid, although their efficacy remains to be evaluated in further clinical trials. The safety of these agents in the more delicate epithelium of the rectum is now being studied. A phase I trial of UC781 revealed no significant adverse events and no significant plasma levels in sexually abstinent men and women applying the microbicide rectally during single and 7-day exposures. ${ }^{27}$ Phase III clinical trials evaluating the efficacy of the dapivirine ring, IPM 009A and IPM 009B, will commence shortly. ${ }^{28}$

Antagonists to $\mathrm{C}-\mathrm{C}$ chemokine receptor type 5 (CCR5), the chemokine co-receptor for HIV entry into the cell, have also been effective as microbicides in macaque studies, ${ }^{29,30}$ as well as in humanized monoclonal mouse models. ${ }^{31}$ See Table 1 for further details of the macaque studies.

From the data available, the lack of systemic absorption of antiretroviral microbicides appears to prevent problems with resistance developing in patients that are using them while unknowingly infected, and safety trials have not revealed any significant adverse reactions. ${ }^{14}$ However, microbicides do not protect against other sexually transmitted infections, which can also facilitate HIV acquisition. ${ }^{32}$ Therefore, antiretroviral microbicides likely will be most effective when used with barrier protection. The use of such microbicides to prevent rectal transmission in both men and women is still under investigation.

Microbicides by themselves are not likely to have a significant impact on decreasing the incidence of HIV globally. Poor adherence, lower efficacy rates and increased cost 

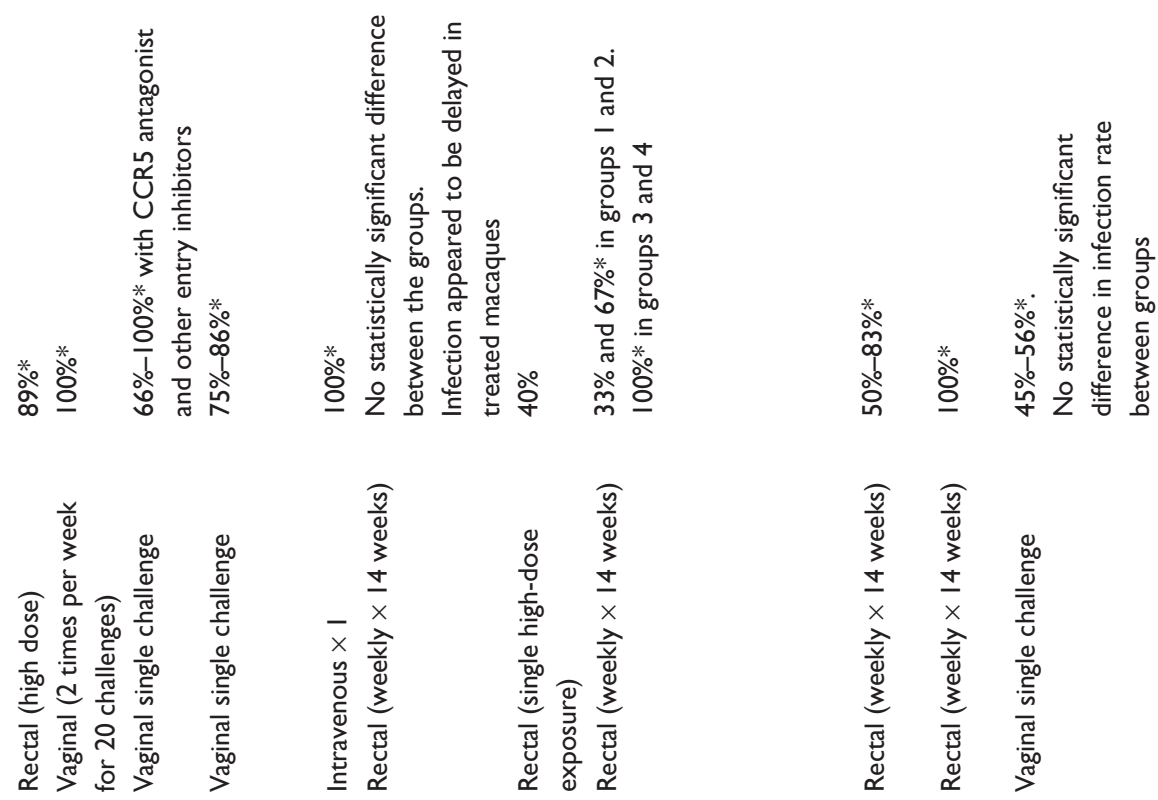

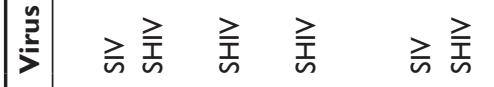

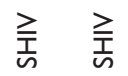
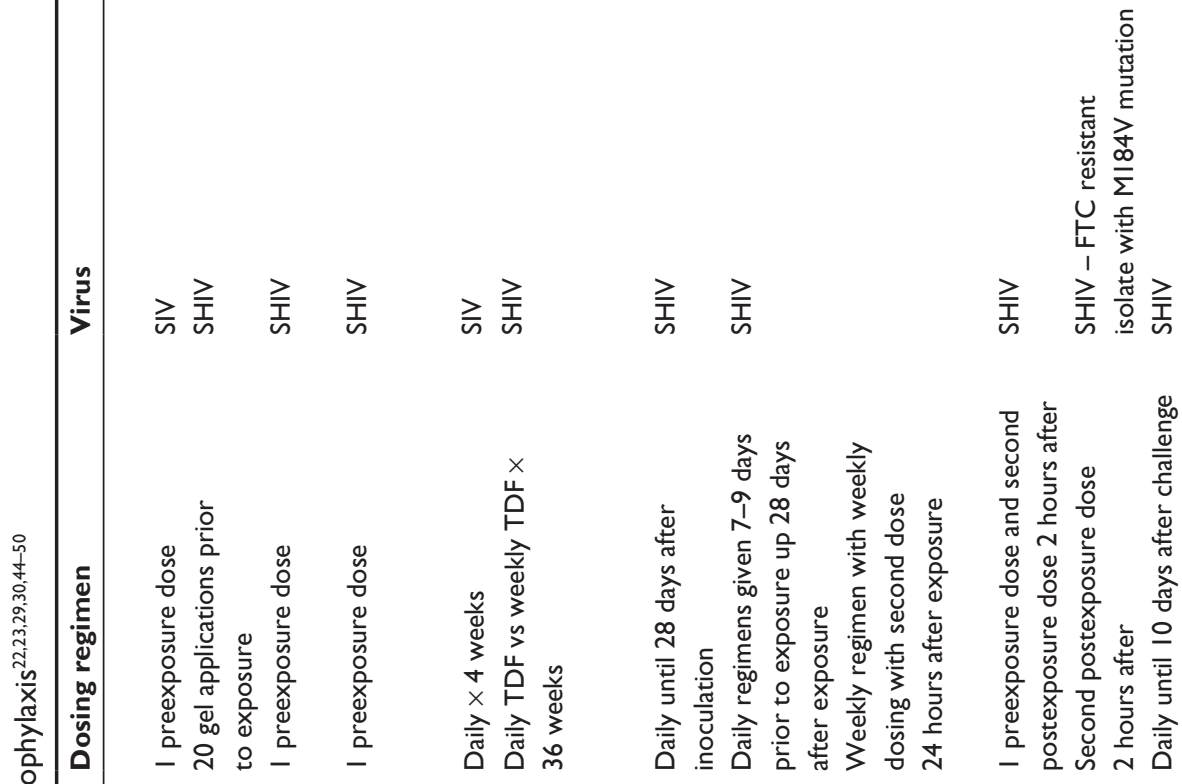

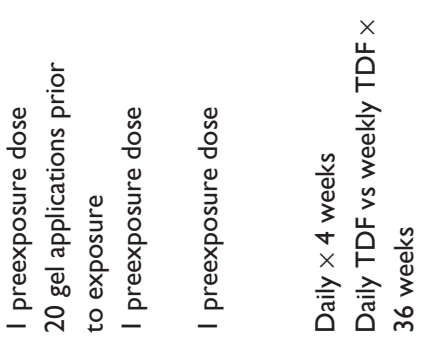
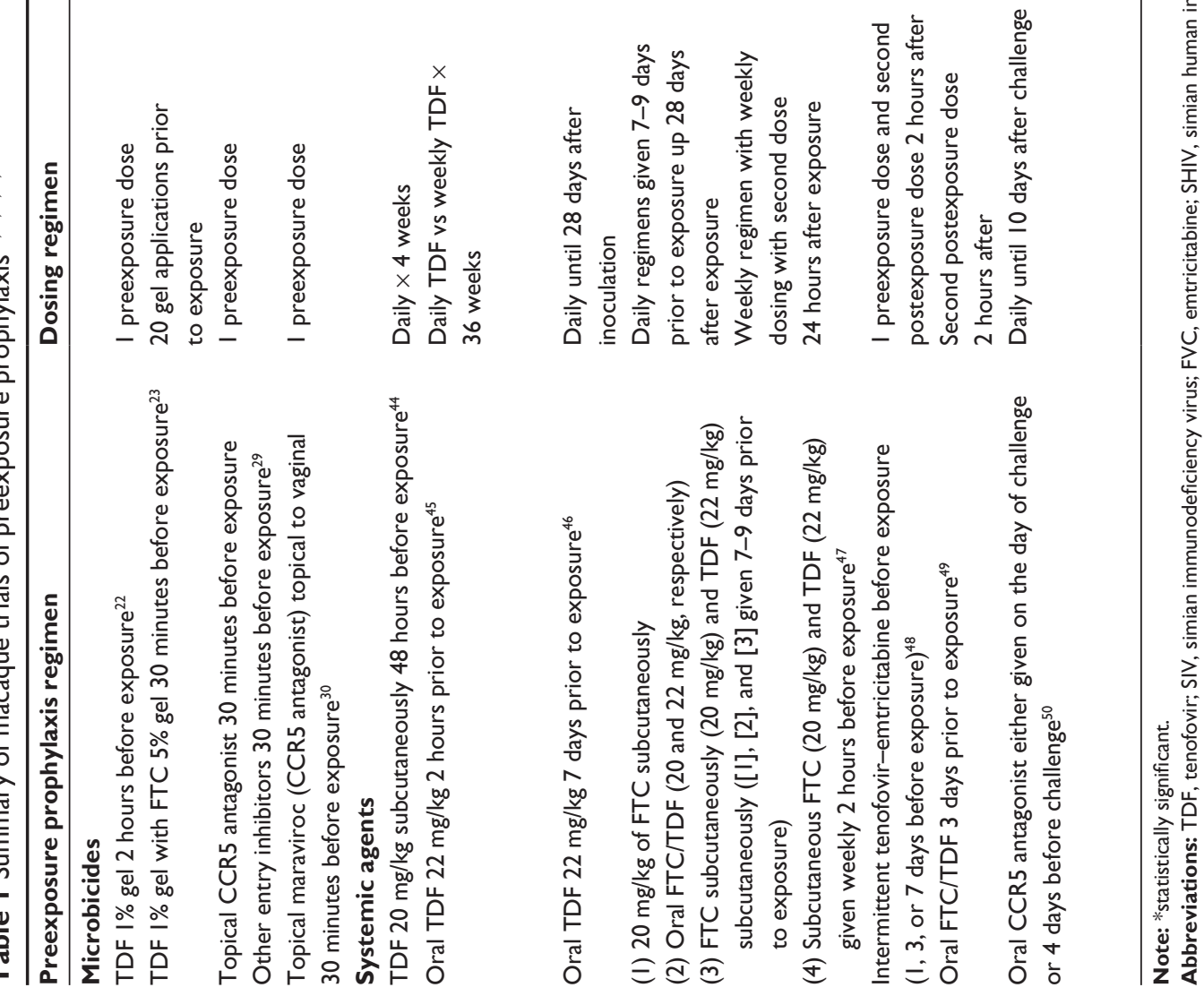
compared to condoms are significant drawbacks. In the Center for the AIDS Programme of Research in South Africa 004 trial, $41 \%$ of women exhibited low adherence, defined as using the gel $<50 \%$ during intercourse. ${ }^{24}$ In day-to-day use outside of a clinical trial, one would expect this number to be even lower, thereby compromising the benefits of this intervention.

\section{Oral prophylaxis}

\section{Theoretical considerations}

\section{with preexposure prophylaxis}

The use of oral antiretroviral drugs as PreP has a foundation in existing knowledge. These agents have been used in preventing perinatal transmission of $\mathrm{HIV}^{4}$ and acquisition of the virus after percutaneous occupational exposures. ${ }^{33}$

It is critical to understand the pathogenesis of HIV in order to understand why PreP works. After exposure to HIV, systemic infection usually does not occur immediately, but is delayed 1-3 days. ${ }^{34}$ During this period, a small population of "founder cells" appear to be responsible for spreading the infection to a cluster of nearby cells, which then leads to viral dissemination and systemic viremia as early as 5 days after exposure. ${ }^{34,35}$ The administration of antiretrovirals for PreP when populations of founder cells are being established may disrupt the infection cycle and help the immune system eradicate the virus.

The choice of an ideal agent for oral PreP is dependent on multiple factors including: (1) whether it acts pre-integration or post-integration (2) the pharmacokinetics of the agent, including its ability to achieve high concentrations in cervicovaginal fluid and the rectum, (3) barriers to resistance, (4) pill burden, and (5) safety and tolerability.

An agent with activity against HIV prior to its establishment in the host cell (ie, pre-integration) would be ideal for use as PreP because it would prevent the establishment of HIV infection in cells. Protease inhibitors are post-integration agents, and their use in this field will likely be limited, although currently there is no available data to support this assertion.

Additionally, the optimal PreP should have ideal pharmacokinetic properties, including rapid distribution and long half-life into tissues. FTC and TDF, for example, both have long intracellular half-lives (40-100 hours), with rapid distribution into tissues, and achieve high concentrations in the cervicovaginal fluid. ${ }^{36,37}$ Studies measuring levels of antiretrovirals in cervicovaginal fluid have shown that NRTIs achieve the highest levels when compared to protease inhibitors and NNRTIs. ${ }^{37}$ More recent data has revealed high concentrations of both maraviroc, a CCR5 antagonist, and raltegravir, an integrase inhibitor, in both the male and female genital tracts. ${ }^{38-41}$ Maraviroc has also achieved high rectal concentration in healthy men. ${ }^{38}$ See Figure 1 for a comparison of these agents and their concentration in the genital tract relative to blood.

Of the antiretroviral agents mentioned, NRTIs and CCR5 antagonists are the most appealing for PreP for the reasons already cited, as well as for their high barrier to resistance and relatively good safety profile. Maraviroc is currently a twicedaily medication, which is a drawback that might hinder larger trials looking at its efficacy for PreP. However, it is unclear whether or not maraviroc could be given once daily for prevention instead of treatment and this needs further

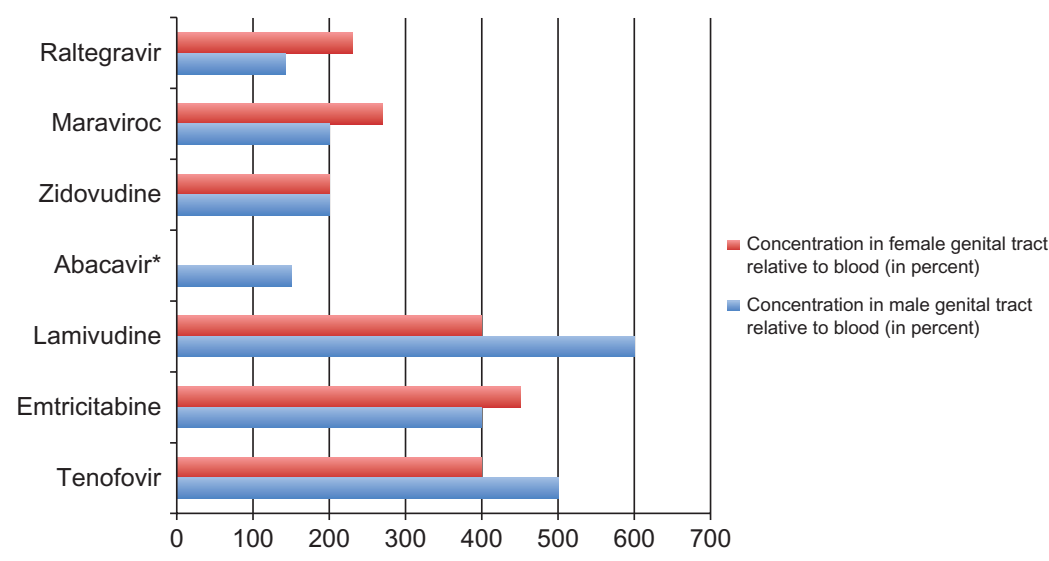

Figure I Concentration of select oral antiretrovirals in the genital tract of men and women relative to blood.

Adapted from references $35-40$.

Notes: In general, the nucleoside reverse transcriptase inhibitors seem to concentrate better in the genital tract of men and women than protease inhibitors and nonnucleoside reverse transcriptase inhibitors (the latter two are excluded from this graph). Some more recent data, although there was significant variability between subjects, shows that raltegravir and maraviroc each can achieve significant levels as well.

*Abacavir achieves lower levels in the female genital tract relative to blood $(\sim 40 \%)$. 
study. Given that CCR5-tropic viruses represent the majority of transmitted viruses, maraviroc may have a unique niche in PreP since it does not form the backbone of current antiretroviral regimens as do the NRTIs.

Once-a-day integrase inhibitors, which block viral integration into the host cell, have been developed. ${ }^{42,43}$ Despite their pre-integration efficacy, integrase inhibitors are not ideal, given their low barrier to resistance, which makes their long-term efficacy questionable. The pharmacokinetics of these agents have also not been as well studied.

For these reasons, the majority of animal studies and clinical trials studying PreP have looked at agents like TDF or FTC/TDF, although oral maraviroc may have a potential role for prophylaxis, which will be discussed.

\section{Preclinical animal studies of PreP}

Both macaque and mouse models have been used to study the potential efficacy of PreP, mainly using TDF and FTC. In macaque monkeys, SIV and SHIV have been used as nonhuman primate models to mimic human immunodeficiency virus. SHIV more closely mimics the various aspects of human infection.

Data from the macaque monkey trials with oral antiretrovirals is summarized in Table $2 .{ }^{44-50}$ Initially, studies in SIV focused on a single agent, TDF, which showed efficacy at preventing $\mathrm{SIV}^{44}$ but, at oral doses comparable to human doses, only revealed partial efficacy at preventing SHIV infection. ${ }^{45,46}$ This prompted many of the most recent animal studies and human clinical trials to look at the combination of FTC/TDF.

In general, the macaque studies have shown that the combination of FTC/TDF can be very effective in preventing the acquisition of SIV and SHIV after oral, rectal, or vaginal exposure. Increased efficacy seems to correlate with increased dosages of antiretrovirals. One study utilizing intermittent weekly dosing of subcutaneous TDF and FTC before and after viral exposure showed equivalent protection from SHIV infection as provided by the same medications given daily. ${ }^{47}$ This study provides a potential foundation for human clinical trials looking at intermittent PreP. The macaque studies have also demonstrated that the use of an oral CCR5 antagonist, CMPD167, can protect a substantial portion of macaques from infection with a CCR5-using SHIV virus. ${ }^{50}$

Humanized mouse models that harbor HIV-susceptible human cells have also been used to examine PreP. Studies using this model have demonstrated the efficacy of TDF and $\mathrm{FTC} / \mathrm{TDF}$ in preventing vaginal, rectal, and intravenous transmission of HIV. ${ }^{51,52}$ One study used this model and demonstrated that oral raltegravir and maraviroc protected against a vaginal HIV-1 challenge. ${ }^{53}$

\section{Clinical studies}

The data from animal studies, as well as the success of antiretrovirals in preventing mother-to-child transmission and postexposure prophylaxis after occupational exposure, has prompted many clinical trials looking at the use of PreP in high-risk HIV populations. To date, these trials have all evaluated the efficacy of either TDF or FTC/TDF.

The first published clinical report of PreP compared daily TDF versus placebo in 936 West African women from Ghana, Cameroon, and Nigeria in preventing HIV transmission via vaginal intercourse. ${ }^{54}$ Two women in the TDF group and six women in the placebo group became infected, but this result was not statistically significant. The study terminated early due to the closure of two of the clinical sites, which limited the planned person-years of follow-up and the power of the study.

The Preexposure Prophylaxis Initiative (iPrEx) study, ${ }^{55}$ a subsequent landmark multinational study, evaluated the safety and efficacy of FTC/TDF in 2499 HIV seronegative men or transgender women who have sex with men, a group with a high number of incident infections worldwide. One hundred patients became infected during follow-up, 36 in the FTC/TDF group and 64 in the placebo group, indicating a statistically significant $44 \%$ prevention efficacy. In subgroup analyses, efficacy was higher among subjects that reported that they had previously had unprotected receptive anal intercourse and those that reported greater than $90 \%$ compliance with pill use. Of those patients in the FTC/TDF group that became infected with HIV, only three had detectable levels of drug in their blood, none with cell-associated drug levels higher than the median levels for seronegative controls.

Preliminary data from additional clinical trials has yielded conflicting data in other high-risk groups. The TDF2 study ${ }^{56}$ followed 1200 heterosexual men and women in Botswana randomized to receive FTC/TDF versus placebo, and found a significantly decreased risk of HIV acquisition (nine patients in the FTC/TDF arm as opposed to 24 patients in placebo). As women are one of the main target groups for PreP, it is important to note that the protective effects of FTC/TDF were seen in both women and men, although the study was underpowered to evaluate sex-based differences. These results are in contrast to the FEM-PrEP trial, a phase III clinical trial of oral FTC/ TDF in nearly 2000 women at high risk for HIV infection. 


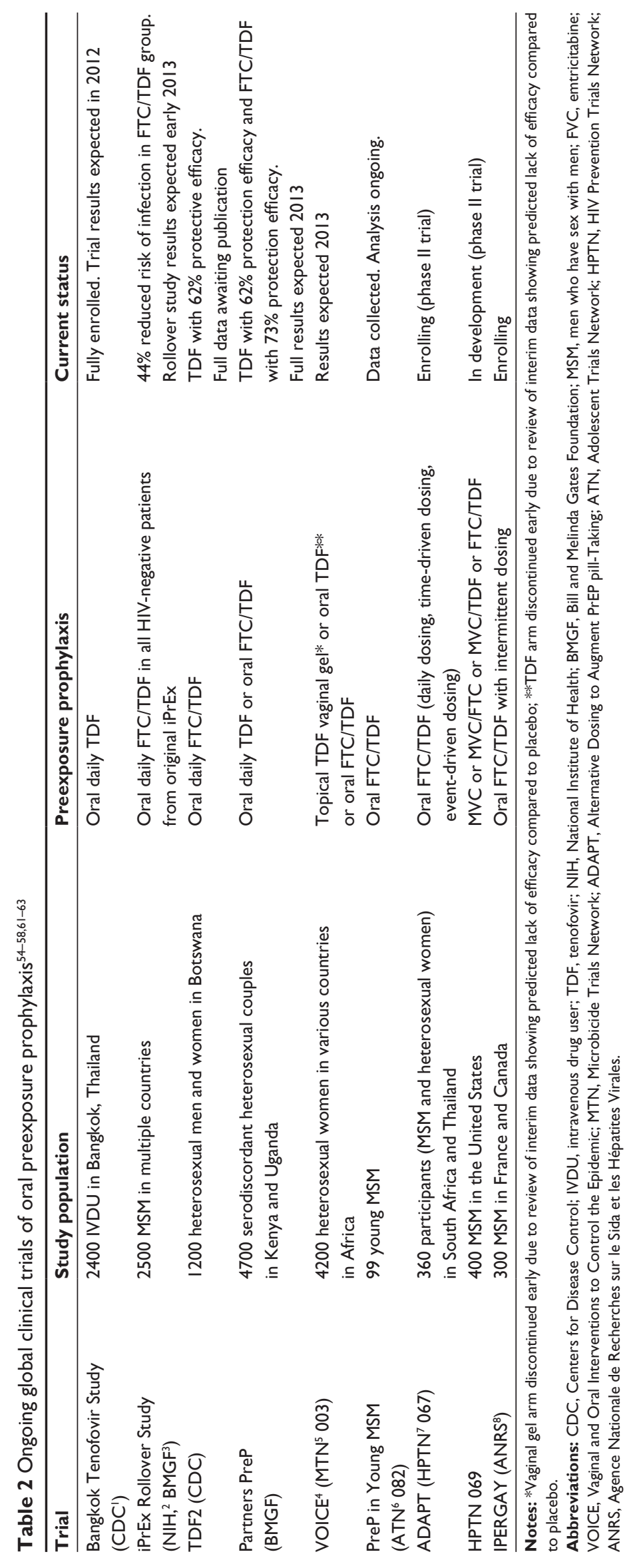


This study was ended prematurely early in April of 2011 after a preliminary review of the data revealed equal rates of infections in the TDF and placebo groups. ${ }^{57}$ The study was deemed unlikely to be able to demonstrate efficacy if continued, and the study is being reviewed to assess the reasons for this surprising result.

Another phase III trial, the Partners PreP study, ${ }^{58}$ compared TDF, FTC/TDF, and placebo in preventing HIV transmission in HIV-discordant heterosexual African couples. Both the TDF and FTC/TDF arms had a statistically significant decreased incidence of HIV infections versus placebo, with a $62 \% \mathrm{HIV}$ protection efficacy noted in the TDF arm and a $73 \%$ protection efficacy noted in the FTC/TDF group.

Like the Partners study, the results of HPTN 052, although not a PreP trial, support the efficacy of early antiretroviral drugs in reducing rates of sexual transmission of HIV-1 among serodiscordant couples. ${ }^{59}$ In this multinational study of 1763 couples, the HIV-infected partners were randomized to receive early antiretroviral therapy or delayed treatment once CD4 criteria were met. Only one of the 28 overall partner-linked infections occurred in the group that was randomized to receive early antiretroviral therapy, which was statistically significant.

The discrepancy between the FEM-PreP trial and the other clinical trials in African countries showing the clinical efficacy of FTC/TDF is worth discussing. The most plausible explanation is that the subjects in FEM-PreP had lower adherence than they self-reported. The measurement of serum levels and the tissue concentration of these drugs are a better means of assessing adherence than self-reporting. There may be other factors that we do not yet understand in the FEM-PreP population that, even with reasonable adherence, might contribute to decreased levels of antiretrovirals systemically and, more importantly, in the cervicovaginal fluid. A recent study, for example, revealed significantly lower levels of tenofovir diphosphate in the vaginal tissue of patients receiving oral tenofovir as opposed to vaginally applied tenofovir. ${ }^{60}$ Achieving levels of active drug in the cervicovaginal tissue is a valid concern, although it does not fully explain the discrepancy between the various studies. The data from the FEM-PreP trial is being analyzed by its investigators to better try to identify the reason for the discordant results in this study compared to others.

With a small number of clinical trials completed showing the efficacy and relative safety of oral PreP with FTC/TDF in high-risk groups for infection with HIV, further studies are in progress ${ }^{61}$ These include studies of MSM, high-risk women, and injection drug users, and evaluate strategies for intermittent PreP. Information on phase II and phase III clinical trials of oral PreP are found in Table 2. One of these trials, the Vaginal and Oral Interventions to Control the Epidemic (VOICE) study, aimed to compare the efficacy of oral tenofovir, oral truvada, and vaginal tenofovir as PreP to each other and to placebo. ${ }^{63}$ During interim reviews by an independent safety board, the trial discontinued both the oral tenofovir arm and the vaginal gel arm since review of the early data indicated lack of efficacy of either compared to placebo ${ }^{63}$ Potential explanations for the lack of efficacy of oral tenofovir include the varying degrees of active tenofovir drug in the cervical tissue of women when administered in an oral formulation and intermittent or poor adherence. ${ }^{60}$

Mathematical models have examined PreP and seen the potential for a significant public health benefit to its implementation, both in the United States and developing countries. With a product demonstrating $90 \%$ efficacy and with $75 \%$ coverage of the general population, models forecast a $74 \%$ decline in the number of cumulative HIV infections in 10 years. ${ }^{64}$ These models are encouraging, but do not factor in some of the important considerations with regard to safety, the development of resistance to PreP medications, and potential changes in sexual-risk behavior over time, considerations that will be discussed.

\section{Considerations for the long-term use of PreP Safety}

Most of the clinical trials looking at the use of FTC/TDF for PreP seem to indicate that use for over a year seems relatively safe. The CAPRISA trial demonstrated that no statistically significant adverse reaction was seen more frequently in the TDF gel group compared to placebo. ${ }^{24}$ With regards to oral PreP, the iPrEx study revealed that the only significant adverse reactions encountered by subjects were nausea and weight loss, with a trend observed of elevated creatinine levels in the FTC/TDF group that was not clinically significant. ${ }^{55}$ It should be noted, however, that the majority of this study population was less than 40 years old. As with populations that tend to make up clinical trials, one could also presume that they would have been a healthier population than the real-world population that would be using these medications. Patients using PreP, therefore, may encounter more side effects or drug-drug interactions than could be expected within the confines of a study. Another important consideration is that we have extensive knowledge about the side-effect profile of FTC/TDF, but there is the potential that medication use in a patient population with an intact immune system could lead 
to unforeseen side effects, as we have seen previously with hepatotoxicity developing in patients with high CD4 counts starting nevirapine. ${ }^{65}$

Safety information available from the Partners PrEP study, the study of West African women, the United States Extended Safety Trial, and the TDF2 study of heterosexual men and women in Botswana all seem to demonstrate shortterm safety of PreP. The Partners PreP prophylaxis trial, for example, only showed increased diarrhea with active agents. ${ }^{61}$ According to the Centers for Disease Control, preliminary data from the US Extended Safety Trial (CDC 4323) of 400 MSM receiving oral tenofovir as PreP also did not raise significant safety concerns. ${ }^{66}$

None of the longer-term cumulative toxicities have been addressed by the clinical trials to date. The trend to an elevated creatinine in the iPrEx with less than perfect adherence study raises concerns for cumulative toxicities including renal failure, tubulointerstitial disease, electrolyte derangements, bone disease, and potential flares of hepatitis B that should not be underestimated. Recently presented and published data has demonstrated reductions in bone mineral density in seronegative men participating in clinical trials with TDF and FTC/TDF. ${ }^{67,68}$ In the tenofovir PreP study among MSM in San Francisco, a statistically significant decline in bone mineral density in the femoral neck and hip was seen compared to placebo. The implications for bone health over longer periods of time in a PreP setting need to be studied further, but one would expect further deteriorations in both health and clinically significant fractures over time.

One area of safety that has been discussed, but not studied extensively, is the impact of the use of TDF and FTC/TDF in cases of hepatitis $\mathrm{B}$ co-infection where the patient is unaware of their hepatitis status. In the TDF trial of West African women, this side effect was not seen. But given the activity of TDF and FTC/TDF against hepatitis B, the incidence of hepatitis B flares, and the development of hepatitis B resistance to these medications, further investigation is required.

\section{Resistance}

One of the biggest concerns with HIV PreP is the development of resistance to these medications in those who become infected. Especially in the developing world, resistance to first- and second-line regimens has significant implications for treatment options for HIV-infected patients. FTC and TDF are two of the most potent and well-tolerated medications used worldwide for HIV treatment, and we cannot lose the ability to prescribe these medications for the treatment of HIV.
FTC has signature resistance mutations at codon 184 with a single nucleotide change that result in amino acid changes from methionine to isoleucine (M184I) or valine (M184V) ${ }^{69,70}$ Either of these mutations confers a high level of resistance to either FTC or lamivudine (3TC). ${ }^{71}$ Monotherapy studies have shown that M184V mutations can develop within approximately 15 days of treatment with lamivudine. ${ }^{70}$ Despite the high level of resistance to these medications, studies have shown that their continuation in regimens does confer a benefit with regard to viral suppression, likely due to decreased replicative capacity of the virus. ${ }^{71,72}$ Additionally, hypersusceptibility to other components of an antiretroviral regimen can occur with these mutations (eg, TDF, zidovudine $[\mathrm{AZT}]) .{ }^{73}$ One animal macaque study exemplified this point by showing that rectal transmission of an FTC-resistant isolate with an $\mathrm{M} 184 \mathrm{~V}$ mutation did not occur in macaques receiving prophylaxis with $\mathrm{FTC/TDF}$, although it did occur in all of the controls. ${ }^{49}$

There are two specific mutations that influence the efficacy of tenofovir: K65R and K70E/G. The K65R mutation involves a change at the second nucleotide codon position from lysine to arginine and causes intermediate-level resistance to tenofovir. ${ }^{74,75}$ There is some data to support that this mutation is more likely to occur in patients with subtype C of HIV, the prevalent subtype seen in Sub-Saharan Africa and India, that are not fully suppressed on their antiretroviral regimen. ${ }^{76,77}$ Single nucleotide alterations in codon 70 lead to an amino acid shift from lysine to glutamate and a second transition required to yield glycine. This produces decreased susceptibility to tenofovir and other antiretrovirals, including FTC. Mutations associated with TDF do not occur as rapidly as the 184V/I with FTC, with monotherapy studies predicting development of these mutations in the 4- to 8-week timeframe. ${ }^{78,79}$

Dual therapy with FTC/TDF in patients who are intermittently adherent to these medications will likely lead to the development of an M184V mutation within several weeks, with almost all patients exhibiting resistance within a year. ${ }^{73,80}$ In the iPrEx study, two of the men had seronegative HIV infection at the time they started to receive active drug, and both were noted to have M184V mutations by week $4 .{ }^{55}$ In the TDF2 study, one participant had unrecognized HIV infection and was subsequently found to develop resistance to both FTC and TDF. ${ }^{54}$ In an area like southern Africa, where the C subtype of HIV predominates, one might expect higher rates of TDF resistance to develop. It will, therefore, be interesting to see the resistance mutations that develop with longer-term follow-up, especially in the trials based in Sub-Saharan Africa. 
An M184V mutation in a patient in the developing world can have significant implications for treatment, since most first-line regimens involve two NRTIs (usually a combination of TDF or AZT and lamivudine or FTC) with an NNRTI. Although the M184V virus would exhibit hypersusceptibility to TDF or AZT and would be less fit for replication, a regimen based on one active NRTI and an NNRTI, given the low barrier to resistance of the NNRTI, runs the risk of treatment failure. One mathematical model looking to predict the effect of PreP on the HIV epidemic in MSM in San Francisco forecasts decreased transmission of HIV, but an increased proportion of new infections caused by resistant strains. ${ }^{81}$

Outside a clinical trial, one could expect more resistant mutations to develop due to poorer adherence and compliance with follow-up. In order to avoid the consequences for resistance in patients on a partially suppressive antiretroviral regimen with undiagnosed infection, regular HIV testing should be linked to the use of PreP. The development of an infrastructure to provide HIV testing at least every 6 months in subjects receiving PreP is critical to prevent resistance with implementation of PreP.

\section{Cost-effectiveness and considerations for the implementation of PreP}

The high cost of implementation of PreP is an important consideration in its potential adoption as a prevention strategy in high-risk populations. The wholesale cost of FTC/TDF is about US\$900 per month, not factoring in other costs, including personnel and infrastructure costs, counseling, routine testing, and surveillance for adverse reactions. ${ }^{82}$ Using data from the iPrEx study, it is estimated that about 44 people would have to receive PreP to prevent one infection, which reflects a cost of over $\$ 500,000$ over a 1 -year period. ${ }^{83}$ This cost is about 20 times the amount that it takes to treat someone with HIV for a year. In this model, PreP is not cost-effective.

It is also unlikely that these medications for PreP will be covered by private insurance, which leaves public financing as the only option for implementing a PreP program. With the current economic downturn, public funding may not be readily available. Some state drug assistance programs set up to treat individuals already infected with HIV are running out of resources, with large waiting lists for antiretroviral treatment. In resource-limited settings, it would seemingly be more difficult to set up the infrastructure for a PreP program and to garner the funds for such an endeavor when there are not sufficient funds to treat individuals already infected with HIV. Currently, the World
Health Organization does not even mandate treatment for HIV-infected partners in serodiscordant couples, despite the results of the HIV Prevention Trials Network 052 study which demonstrated that treatment of the HIV-infected partner in serodiscordant couples has a significant impact on decreasing transmission of HIV. ${ }^{59}$

Aside from the lack of cost-effectiveness of a PreP strategy, there are other important public health and population considerations for implementation. This includes the optimal target group for treatment (high-risk MSM participating in receptive anal intercourse, female and male sex workers). Which practitioners would be in a position to offer PreP? What training would they require? Also, one would need to decide whether to use a daily-pill strategy or an intermittentpill strategy, the latter model showing efficacy in animal models but not yet in humans.

PreP may have implications on an individual level as well. Concerns have been raised that the availability of PreP may lead to more risky sexual practices through behavioral disinhibition, also known as risk compensation. ${ }^{84}$ The concept is that people might feel protected by PreP and stop using barrier methods of protection, which have been proven to be more efficacious. Risk compensation has not yet been seen in placebo-controlled clinical trials, although some data exists that it is a genuine concern in high-risk populations. ${ }^{85}$ The attitudes of high-risk individuals to PreP, actual levels of adherence, and the role of risk compensation need to be studied further. In the clinical trials of PreP already completed, other preventive strategies for decreasing HIV transmission are reinforced to subjects as part of the study protocol. It is not yet clear whether or not these same measures would be built into a program for PreP in a real-world setting.

\section{Future areas of interest}

The role of PreP as a strategy that can be widely implemented for HIV prevention remains to be determined. From a research standpoint, there are other drugs and molecules that could be and are being evaluated in clinical studies for PreP, including CCR5 antagonists. Biologic molecules that have an effect on CCR5 expression could potentially be another area of interest that will help avoid the concerns about antiretroviral drug resistance.

Despite the data that has demonstrated the efficacy of PreP in higher-risk populations, there are many unknown factors with regards to longer-term use of oral antiretrovirals for PreP, including safety and resistance concerns. Equally important, there are significant public health concerns relating to the implementation of such a strategy. PreP needs to 
be evaluated alone and in combination with other approaches such as universal testing and early treatment of HIV infections to determine the best means to decrease the incidence of HIV infections worldwide.

\section{Disclosure}

$\mathrm{AM}$ and RRR report no conflicts of interest. BLG has received honoraria from Gilead and Viiv Healthcare within the past 3 years.

\section{References}

1. UNAIDS. AIDS Epidemic Update. Geneva: UNAIDS/WHO; 2009.

2. Cohen MS, Chen YQ, McCauley M, et al; for HPTN 052 Study Team. Prevention of HIV-1 infection with early antiretroviral therapy. N Engl J Med. 2011;365(6):493-505. Epub July 18, 2011.

3. Anglemeyer A, Rutherford GW, Egger M, Siegfried N. Antiretroviral therapy for prevention of HIV transmission in HIV-discordant couples. Cochrane Database Sys Rev. 2011;11(5):CD009153.

4. Volmink J, Siegfried NL, van Der Merwe L, Brocklehurst P. Antiretrovirals for reducing the risk of mother-to-child transmission of HIV infection. Cochrane Database Sys Rev. 2007;1:CD003510.

5. Smith DK, Grant RM, Weidle PJ, Lansky A Mermin J, Fenton KA. Interim guidance: Preexposure prophylaxis for the prevention of HIV infection in men who have sex with men. MMWR Morb Mortal Wkly Rep. 2011;60(3):65-68.

6. Hall HI, Song R, Rhodes P, et al; for HIV Incidence Surveillance Group. Estimation of HIV incidence in the United States. JAMA. 2008;300: $520-529$.

7. Kelesedis T, Landovitz RJ. Preexposure prophylaxis for HIV prevention. Curr HIV/AIDS Rep. 2011;8:94-103.

8. Stein ZA. HIV prevention: the need for methods women can use. Am J Pub Health. 1990;80:460-462.

9. Cutler B, Justman J. Vaginal microbicides and the prevention of HIV transmission. Lancet Infect Dis. 2008;8:685-697.

10. Pearce-Pratt R, Phillips D. Sulfated polysaccharides inhibit lymphocyteto-epithelial transmission of human immunodeficiency virus-1. Biol Reprod. 1996;54(1):173-182.

11. Scordi-Bello I, Mosoian A, He C, et al. Candidate sulfonated topical microbicides; comparison of antihuman immunodeficiency virus activities and mechanisms of action. Antimicrob Agents Chemother. 2005;49: 3607-3615.

12. Rusconi S, Moonis M, Merrill SP, et al. Naphtalene sulfonate polymers with CD4-blocking and anti-human immunodeficiency virus type 1 activities. Antimicrob Agents Chemother. 1996;40:234-236.

13. Bourne N, Bernstein D, Ireland J, Sonderfan AJ, Profy AT, Stanberry LR. The topical microbicide PRO 2000 protects against genital herpes in a mouse model. J Infect Dis. 1999;180:203-205.

14. Ramjee, G, Kamali A, McCormack S. The last decade of microbicide trials in Africa: from hypothesis to facts. AIDS. 2010;24(Suppl 4): S40-S49.

15. Skoler-Karpoff S, Ramjee G, Ahmed K, et al. Efficacy of Carraguard for prevention of HIV infection in women in South Africa: a randomised double-blind placebo-controlled trial. Lancet. 2008;372: 1977-1987.

16. Van Damme L, Govinden R, Mirembe F, et al; for CS Study Group. Lack of effectiveness of cellulose sulfate gel for the prevention of vaginal HIV transmission. $N$ Engl J Med. 2008;359:463-472.

17. Halpern V, Ogunsola F, Obunge O, et al. Effectiveness of cellulose sulfate vaginal gel for the prevention of HIV infection: results of a phase III trial in Nigeria. PLoS One. 2008;3(11):e3784. Epub November 21, 2008.
18. Abdool Karim S, Raichardson BA, Ramjee G, et al; for HIV Prevention Trials Network (HPTN) 035 Study Team. Safety and effectiveness of BufferGel and $0.5 \%$ PRO2000 gel for the prevention of HIV infection in women. AIDS. 2011;25(7):957-966.

19. McCormack S, Ramjee G, Kamall A, et al. Pro2000 vaginal gel for prevention of HIV-1 infection (Microbicides Development Programme 301): a phase 3 randomised, double-blind, parallel group trial. Lancet. 2010;376(9749):1329-1337. Epub September 17, 2010.

20. Mesquita PM, Cheshenko N, Wilson SS, et al. Disruption of tight junctions by cellulose sulfate facilitates HIV infection: model of microbicide safety. J infect Dis. 2009;200:599-608.

21. Van Damme L, Ramjee G, Alary M et al; for COL-1492 Study Group. Effectiveness of COL-1492, a nonoxynol-9 vaginal gel, on HIV-1 transmission in female sex workers: a randomized controlled trial. Lancet. 2002;360:971-977.

22. Cranage M, Sharpe S, Herrera C, et al. Prevention of SIV rectal transmission and priming of $\mathrm{T}$ cell responses in macaques after local pre-exposure application of tenofovir gel. PLoS Med. 2008;5:e157.

23. Parikh U, Dobard C, Sharma S, et al. Complete protection from repeated vaginal simian-human immunodeficiency virus exposures in macaques by a topical gel containing tenofovir alone or with emtricitabine. JVirol. 2009;83(20):10358-10365. Epub August 5, 2009.

24. Abdool KQ, Abdool Karim SS, Frolich JA, et al; for CAPRISA 004 Trial Group. Effectiveness and safety of tenofovir gel, an antiretroviral microbicide, for the prevention of HIV infection in women. Science. 2010;329(5996):1168-1174. Epub July 19, 2010.

25. Nel AM, Coplan P, Van de Wijgert JH, et al. Safety, tolerability and systemic absorption of dalpivirine vaginal microbicide in healthy HIVnegative women. AIDS. 2009;23:1531-1538.

26. Schwartz JL, Kovalevsky G, Lai J-J, et al. A randomized six-day study of an antiretroviral microbicide candidate UC781, a nonnucleoside reverse transcriptase inhibitor. Sex Trans Dis. 2008;35(4): 414-419.

27. Anton PA, Saunders T, Elliot J, et al. First phase 1 double-blind, placebo-controlled randomized rectal microbicide using UC781 gel with a novel index of ex vivo efficacy. PLoS One. 2011;6(9):e23243. Epub September 28, 2011.

28. IPMglobal.org [homepage on the Internet]. Maryland: International Partnership for Microbicides; c2002-11. Available from: http://www. ipmglobal.org/publications-media/novel-technology-microbicide-ring. Accessed December 8, 2011.

29. Veazey RS, Klasse PJ, Schader SM, et al. Protection of macaques from vaginal SHIV challenge by vaginally delivered inhibitors of virus cell fusion. Nature. 2005;438:99-102. Epub October 30, 2005.

30. Veazey RS, Ketas RJ, Dufour J, et al. Protection of rhesus monkeys from vaginal infection by vaginally-delivered maraviroc, an inhibitor of HIV-1 entry via the CCR5 co-receptor. J Infect Dis. 2010;102(5): 739-744.

31. Neff CP, Kurisu T, Ndolo T, Fox K, Akkina R. A topical microbicide gel formulation of CCR5 antagonist maraviroc prevents HIV-1 vaginal transmission in humanized RAG-hu mice. PloS One. 2011;6(6):e20209. Epub June 1, 2011.

32. Cohen, MS. HIV and sexually transmitted diseases: lethal synergy. Top HIV Med. 2004;12(4):104-107.

33. Smith DK, Grohskopf LA, Black RJ, et al; for US Department of Health and Human Services. Antretroviral postexposure prophylaxis after sexual, injection-drug use, or other nonoccupational exposure to HIV in the United States: recommendations from the US Department of Health and Human Services. MMWR Recomm Rep. 2005;54(RR-2):1-20.

34. McMichael AJ, Borrow P, Tomaras GD, Goonetilleke N, Haynes BF. The immune response during acute HIV-1 infection: clues for vaccine development. Nat Rev Immunol. 2010;10:11-23.

35. Romanelli F, Murphy B. Systemic preexposure prophylaxis for human immunodeficiency virus infection. Pharmacotherapy. 2010;30(10): $1021-1030$. 
36. Dumond JB, Yeh RF, Patterson KB, et al. Antiretroviral drug exposure in the female genital tract: implications for oral pre- and post-exposure prophylaxis. AIDS. 2007;21:1899-1907.

37. Cohen MS, Gay C, Kashuba A, Blower S, Paxton L. Narrative review: Antiretroviral therapy to prevent the sexual transmission of HIV-1. Ann Intern Med. 2007;146:591-601.

38. Brown KC, Patterson KB, Malone SA. Single and multiple dose pharmacokinetics of maraviroc in saliva, semen, and rectal tissue of healthy HIV-negative men. J Infect Dis. 2011;203(10): 1484-1490.

39. Dumond JB, Patterson KB, Pecha AL, et al. Maraviroc concentrates in the cervicovaginal fluid and vaginal tissue of HIV-negative women. J Acquir Immune Defic Syndr. 2009;51(5):546-553.

40. Clavel C, Peytavin G, Tubiana R, et al. Raltegravir concentrations in the genital tract of HIV-1 infected women with a raltegravir-containing regimen (DIVA 01 study). Antimicrob Agents Chemother. 2011;55(6): 3018-3021.

41. Barau C, Delaugerre C, Draun J, et al. High concentration of raltegravir in semen of HIV-infected men: results from a substudy of the EASIERANRS 138 trial. Antimicrob Agents Chemother. 2010;54(2):937-939. Epub December 7, 2009.

42. Molina JM, Lamarca A, Andrade-Villanueva, et al; for Study 145 Team. Efficacy and safety of once daily elvitegravir versus twice daily raltegravir in treatment-experienced patients with HIV-1 receiving a ritonavir-boosted protease inhibitor: randomised, double-blind, phase 3, non-inferiority study. Lancet Infect Dis. 2012;12(1):27-23. Epub October 18, 2011.

43. Van Lunzen J, Maggiolo F, Arribas JR, et al. Once daily dolutegravir (S/GSK1349572) in combination therapy in antiretroviral-naive adults with HIV: planned interim 48 week results from SPRING-1, a dose-ranging randomised, phase $2 \mathrm{~b}$ trial. Lancet Infect Dis. Epub October 20, 2011.

44. Tsai CC, Follis KE, Sabo A, et al. Prevention of SIV infection in macaques by (R)-9-(2-phosphonylmethoxypropyl)adeninine. Science. 1995;270(5239):1197-1199.

45. Subbarao S, Otten RA, Ramos A, et al. Chemoprophylaxis with tenofovir disoproxil fumarate provided partial protection against infection with simian human immunodeficiency virus given multiple virus challenges. J Infect Dis. 2006;194:904-911.

46. Subarrao S, Ramos A, Kim C, et al. Direct stringency comparison of two macaque models (single-high vs repeat-low) for mucosal HIV transmission using an identical anti-HIV chemoprophylaxis intervention. $J \mathrm{Med}$ Primatol. 2007;36(4-5):238-243.

47. García-Lerma JG, Otten RA, Qari SH, et al. Prevention of rectal SHIV transmission in macaques by daily or intermittent prophylaxis with emtricitabine and tenofovir. PLoS Med. 2008;5(2):e28.

48. García-Lerma JG, Cong ME, Mitchell J, et al. Intermittent prophylaxis with truvada protects macaques from rectal SHIV infection. Sci Transl Med. 2010;2(14):14ra4.

49. Cong M, Youngpairoj AS, Zheng Q, et al. Protection against rectal transmission of an emtricitabine-resistant simian/human immunodeficiency virus SHIV162p3M184V mutant by intermittent prophylaxis with Truvada. J Virol. 2011;85(15):7933-7936. Epub June 1, 2011.

50. Veazey RS, Springer MS, Marx PA, Dufour J, Klasse PJ, Moore JP. Protection of macaques from vaginal SHIV challenge by an orally delivered CCR5 inhibitor. Nat Med. 2005;11(12):1293-1294.

51. Denton PW, Estes JD, Sun Z, et al. Anitretroviral pre-exposure prophylaxis prevents vaginal transmission of HIV-1 in humanized BLT mice. PLoS Med. 2008;5(1):e16.

52. Denton PW, Krisko JF, Powell DA, et al. Systemic administration of anitretrovirals prior to exposure prevents rectal and intravenous HIV-1 transmission in humanized BLT mice. PLoS One. 2010;5(1):e8829.

53. NeffC, Ndolo T, Tandon A, Habu Y, Akkina R. Oral pre-exposure prophylaxis by raltegravir and maraviroc protects against vaginal HIV-1 transmission in a humanized mouse model. PloS One. 2010;5(12):e15257.
54. Peterson L, Taylor D, Roddy R, et al. Tenofovir disoproxil fumarate for prevention of HIV infection in women: a phase 2, double-blind, randomized placebo-controlled trial. PLoS Clin Trials. 2007;2(5):e27.

55. Grant RM, Lama JR, Anderson PL, et al; for iPrEx Study Team. Preexposure chemoprophylaxis for HIV prevention in men who have sex with men. N Engl J Med. 2010;363(27):2587-2599. Epub November 23, 2010.

56. Thigpen MC, Kebaabetswe PM, Smith DK, et al; for the TDF2 Study Group. Daily oral antiretroviral use for the prevention of HIV infection in heterosexually active young adults in Botswana: results from the TDF2 study [abstractWELBC01]. From: 6th IAS Conference on HIV Pathogenesis, Treatment, and Prevention; July 17-20, 2011; Rome, Italy. International AIDS Society; 2011.

57. [No authors listed] Early end for FEM-Pr-EP HIV prevention trial. AIDS Patient Care STDS. 2011;25(6):383.

58. Baeten J, Celum C. Antiretroviral pre-exposure prophylaxis for HIV-1 prevention among heterosexual African men and women: the Partners PrEP study [abstract MOAX0106]. From: 6th IAS Conference on HIV Pathogenesis, Treatment, and Prevention; July 17-20, 2011; Rome, Italy. International AIDS Society; 2011.

59. Cohen MS, Chen YQ, McCauley M, et al; for HPTN 052 Study Team. Prevention of HIV-1 infection with early antiretroviral therapy. $N$ Engl J Med. 2011;365(6):493-505. Epub July 18, 2011.

60. Hendrix C, Minnis A, Guddera V, et al; for MTN-001 Study Team. MTN-001: A phase 2 cross-over study of daily oral and vaginal TFV in healthy, sexually active women results in significantly different product acceptability and vaginal tissue concentrations [Abstract 35LB]. From: 18th Conference on Retroviruses and Opportunistic Infections; February 27-March 2, 2011; Boston, MA. Available from: http://www.retroconference.org/2011/Abstracts/42418.htm. Accessed December 26, 2011.

61. Veronese F, Turpin JA, Feuer C. Beyond 2010: Gaps, Challenges, and Priorities for the Future of Preclinical HIV Preexposure Prophylaxis (PrEP): Summary of the October 20-21, 2009 Workshop. AIDS Res Hum Retroviruses. 2010;26(11):1-8.

62. HPTN Studies [study page on the Internet]. HIV Prevention Trials Network. c2010. Available from http://ww.hptn.org/research_studies. asp. Accessed November 1, 2011.

63. Avac.org [homepage on the Internet]. New York: AVAC: Global Advocacy for HIV Prevention; c2011. Available from: http://www. avac.org. Accessed December 5, 2011.

64. Abbas UL, Anderson RM, Mellors JW. Potential impact of antiretroviral therapy on HIV-1 transmission and AIDS mortality in resource-limited settings. J Acquir Immune Defic Syndr. 2006;41(5):632-641.

65. Patel SM, Johnson S, Belknap SM. Severe adverse cutaneous and hepatic toxicities associated with nevirapine use by non-HIV-infected individuals. J Acquir Immune Def Syndr. 2004;35(2):120-125.

66. Cdc.gov. Preliminary results from first safety study of daily tenofovir for HIV prevention among MSM find no significant concerns. Atlanta, GA: CDC. [updated December 8, 2011] Available from: (www.cdc. gov/hiv/prep/resources/factsheets/extended_PrEB-safety-trial.htm) July 23, 2010. Accessed November 1, 2011.

67. Liu A, Vittinghoff E, Irby R, et al. Bone mineral density in HIV-negative men participating in a tenofovir pre-exposure prophylaxis randomized clinical trial in San Francisco. PLoS One. 2011;6(8):e23688.

68. Mulligan K, Glidden D, Gonzales P, et al. Effects of FTC/TDF on bone mineral densty in seronegative men from 4 continents: DEXA results of the global iPrEx Study [Abstract 94 LB]. Presented at the 18th Conference on Retroviruses and Opportunistic Infections (CROI). Boston, USA, February 27 to March 2, 2011.

69. Boucher CA, Cammack N, Schipper P, et al. High-level resistance to (-) enantiomeric 2\#-deoxy-3\#-thiacytidine in vitro is due to one amino acid substitution in the catalytic site of human immunodeficiency virus type 1 reverse transcriptase. Antimicrob Agents Chemother. 1993;37:2231-2234. 
70. Tisdale M, Kemp SD, Parry NR, Larder BA. Rapid in vitro selection of human immunodeficiency virus type 1 resistant to 3 '-thiacytidine inhibitors due to a mutation in the YMDD region of reverse transcriptase. Proc Natl Acad Sci U S A. 1993;90:5653-5666.

71. Miller V, Stark T, Loeliger AE, Lange JM. The impact of the M184V substitution in HIV-1 reverse transcriptase on treatment response. HIV Med. 2002;3:135-145.

72. Whitcomb JM, Parkin NT, Chappey C, Hellmann NS, Petropoulos CJ. Broad nucleoside reverse-transcriptase inhibitor cross-resistance in human immunodeficiency virus type 1 clinical isolates. J Infect Dis. 2003;188:992-1000.

73. Rousseau FS, Kahn JO, Thompson M, et al. Prototype trial design for rapid dose selection of antiretroviral drugs: an example using emtricitabine (Coviracil). J Antimicrob Chemother. 2001;48:507-513.

74. Brenner BG, Coutsinos D. The K65R mutation in HIV-1 reverse transcriptase: genetic barriers, resistance profile and clinical implications. HIV Ther. 2009;3(6):583-594.

75. Shafer RW, Schapiro JM. HIV-1 drug resistance mutations: an updated framework for the second decade of HAART. AIDS Rev. 2008;10:67-84.

76. Doualla-Bell F, Avalos A, Brenner B, et al. High prevalence of the K65R mutation in human immunodeficiency virus type 1 subtype $\mathrm{C}$ isolates from infected patients in Botswana treated with didanosine-based regimens. Antimicrob Agents Chemother. 2006;50:4182-4185. Epub October 2, 2006.

77. Hurt CB, Eron JJ, Cohen MS. Pre-exposure prophylaxis and antiretroviral resistance: HIV prevention at a cost? Clin Infect Dis. 2011;53(12):1265-1270.
78. Louie M, Hogan C, Hurley A, et al. Determining the antiviral activity of tenofovir disoproxil fumarate in treatment-naive chronically HIV-1-infected individuals. AIDS. 2003;17:1151-1156.

79. Van Rompay KK, Johnson JA, Blackwood EJ, et al. Sequential emergence and clinical implications of viral mutants with K70E and $\mathrm{K} 65 \mathrm{R}$ mutation in reverse transcriptase during prolonged tenofovir monotherapy in rhesus macaques with chronic RT-SHIV infection. Retrovirology. 2007;4:25.

80. Kuritzkes DR, Quinn JB, Benoit SL, et al. Drug resistance and virologic response in NUCA 3001, a randomized trial of lamivudine (3TC) versus zidovudine (ZDV) versus ZDV plus $3 \mathrm{TC}$ in previously untreated patients. AIDS. 1996;10(9):975-981.

81. Supervie V, García-Lerma JG, Heneine W, Blower S. HIV, transmitted drug resistance, and the paradox of the preexposure prophylaxis. Proc Natl Acad Sci U S A. 2010;107(27):12381-12386.

82. Leibowitz AA, Parker, KB, Rotheram-Borus MJ. A US policy perspective on oral preexposure prophylaxis for HIV. Am J Public Health. 2011;101(6):982-985. Epub April 14, 2011.

83. Lee DH, Vielemeyer O. Preexposure chemoprohylaxis for HIV prevention (letter to the editor). New Engl J Med. 2011;364(14):1372-1373.

84. Myers GM, Mayer KH. Oral preexposure anti-HIV prophylaxis for high risk US populations: current considerations in light of new findings. AIDS Patient Care STDS. 2011;25(2):63-67.

85. Golub SA, Kowalczyk W, Weinberger CL, Parsons JT. Preexposure prophylaxis and predicted condom use among high-risk men who have sex with men. J Acquir Immune Defic Syndr. 2010;54(5):548-555.
HIV/AIDS - Research and Palliative Care

\section{Publish your work in this journal}

HIV/AIDS - Research and Palliative Care is an international, peerreviewed open-access journal focusing on advances in research in HIV, its clinical progression and management options including antiviral treatment, palliative care and public healthcare policies to control viral spread. The journal welcomes original research, basic science,

\section{Dovepress}

clinical \& epidemiological studies, reviews \& evaluations, expert opinion \& commentary, case reports \& extended reports. The manuscript management system is completely online and includes a very quick and fair peer-review system. Visit http://www.dovepress.com/ testimonials.php to read real quotes from published authors. 